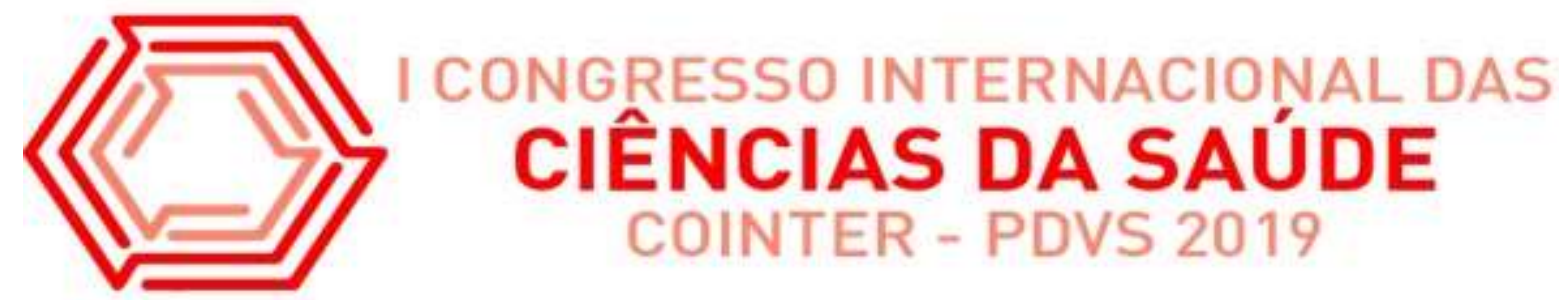

\title{
RIZOPHORA MANGLE E ÁCIDO TÂNICO :UMA ASSOCIAÇÃO EM CREME PARA O TRATAMENTO DE FERIDAS
}

\section{RIZOPHORA MANGLE Y TANNIC ACID: UNA ASOCIACIÓN EN CREMA PARA LA CURACIÓN DE HERIDAS}

\section{RIZOPHORA MANGLE AND TANNIC ACID:AN ASSOCIATION IN CREAM TO WOUND HEALING}

\author{
Apresentação: Comunicação Oral
}

Anneliese Gonçalves Costa Marinho'; Leila Leal Bastos²; Ivone Antônia de Souza ${ }^{3}$;Otacílio Antunes Santana ${ }^{4}$; Jeymesson Raphael Cardoso Vieira ${ }^{5}$

DOI: https://doi.org/10.31692/ICOINTERPDVS.2019.0006

\begin{abstract}
Resumo
\footnotetext{
${ }^{1}$ Ciências Biológicas, UFPE, annelisecosta7@gmail.com

2 Farmácia, UFPE, leila.leal@nudfac.com.br

${ }^{3}$ Ciências Biológicas, UFPE, otacilio.santana@gmail.com

${ }^{4}$ Farmácia, UFPE, idesouza5@gmail.com

${ }^{5}$ Biomedicina, UFPE, jeymesson@gmail.com
}

Os manguezais são áreas ricas em recursos economicamente importantes explorados pela população costeira humana. Rizophora mangle (Rhizophoraceae) é uma das espécies encontradas nos manguezais e é usada na medicina popular no tratamento de diarreia, cicatrização, anti-inflamatório. O ácido tânico que também é um componente encontrado na natureza é usado popularmente como Antioxidante, adstringente, bactericida, cicatrização. Este estudo teve como objetivo investigar a atividade antibacteriana da associação do extrato aquoso de folhas de R.mangle(EAFRm)associado ao ácido tânico a 5\%. Trata-se de um estudo que induz a ferida de primeira intenção para avaliar o potencial cicatrizante quando tratada com alguns fármacos, como,NACL,Creme lannete a 4\%,dexpantenol a 5\% e o creme de associação descrito acima(EAFRm). O material botânico foi coletado no Mangue da cidade de Itamaracá, distrito de Vila Velha no estado de Pernambuco - Brasil autorizado pela Empresa de Controle de Poluição Ambiental e Administração de Recursos Hídricos (CA DFRB N. 120/2014 ${ }^{\circ}$ ). O extrato foi preparado por trituração de folhas frescas. A infusão foi preparada com água destilada $\left(40^{\circ} \mathrm{C}\right.$ por 10 minutos) e filtrado. Em seguida , foi removido para L101 da marca Liobrás. Após este procedimento, o resíduo seco do extrato foi armazenado a $5^{\circ} \mathrm{C}$. A obtenção do ácido tânico $(250 \mathrm{~g})$ foi realizada em forma de pó hidrossolúvel com teor de ácido gálico (base seca) Max. 3,0\%/ Densidade 0,35 0,45g/cm3/ pH (1\% em água) 3,0 4,0/ Solubilidade (20\% em água). O creme foi produzido a $5 \%$ incorporado ao extrato de Rizophora mangle ao ácido tânico.Foram selecionadas 20 ratas wistar (Rattus 
novergicus) com 8 semanas ,as quais foram divididas em 5 grupos distintos.O projeto foi aprovado no Comitê de Ética sob o n²3076.027569./2017-91.

Foi feita a indução das feridas cutâneas que foram tratadas e observadas através do exame clínico,análise morfométrica e análise histomorfométrica.Feridas cutâneas foram induzidas e ,em seguida ,tratadas com avaliação clínica .Após o procedimento ,realizou-se análise morfométrica e histomorfométrica.Dentre os grupos e avaliados foi observado que o grupo de associação de EAFRm ao ácido tânico a 5\% apresentou grau de retração e de reeptelização com maior potencial de cicatrização quando comparado aos demais grupos.O estudo evidenciou a importância da realização histomorfométrica na correlação com os achados encontrados.

Palavras-Chave: Rizophora mangle, ácido tânico,poder cicatrizante,análise morfométrica,análise histomorfométrica.

\section{Resumen}

Los manglares son áreas económicamente importantes y ricas en recursos explotadas por la población humana costera. Rizophora mangle (Rhizophoraceae) es una de las especies que se encuentran en los manglares y se usa en medicina popular para tratar la diarrea, cicatrices, antiinflamatorios.El ácido tánico, que también es un componente que se encuentra en la naturaleza, se usa popularmente como antioxidante, astringente, bactericida, Este estudio tuvo como objetivo investigar la actividad antibacteriana de la asociación de extracto de hoja acuosa de R.mangle (EAFRm) asociado con ácido tánico al 5\%. Este es un estudio que induce a la herida de primera intención a evaluar el potencial de curación cuando se trata con algunos medicamentos, como NACL, crema de lannete al 4\%, dexpantenol al 5\% y la crema combinada descrita anteriormente (EAFRm). El material botánico fue recolectado en el manglar de la ciudad de Itamaracá, distrito de Vila Velha en el estado de Pernambuco - Brasil autorizado por la Compañía de Control de Contaminación Ambiental y Gestión de Recursos Hídricos (CA DFRB N. 120 / 2014º). El extracto se preparó triturando hojas frescas, la infusión se preparó con agua destilada $\left(40^{\circ} \mathrm{C}\right.$ durante 10 minutos) y se filtró. Luego se eliminó a L101 de la marca Liobras. Después de este procedimiento, el residuo del extracto seco se almacenó a $5^{\circ} \mathrm{C}$. El ácido tánico $(250 \mathrm{~g})$ se obtuvo como un polvo soluble en agua con contenido de ácido gálico (base seca) Máx. 3,0\% / Densidad 0,35 0,45 g / cm3 / pH (1\% en agua) 3, 04.0 / Solubilidad (20\% en agua). La crema se produjo al 5\% incorporada en el extracto de Rizophora mangle a ácido tánico. Veinte ratas wistar (Rattus novergicus) de 8 semanas de edad fueron seleccionadas y divididas en 5 grupos distintos. El proyecto fue aprobado por el Comité de Ética bajo el número 23076 .027569. / 2017-91.Inducción de heridas de la piel que fueron tratadas y observadas a través del examen clínico, análisis morfométrico y análisis histomorfométrico. Las heridas de la piel fueron inducidas y luego tratadas con evaluación clínica. Después del procedimiento, se realizaron análisis morfométricos e histomorfométricos. Se observó que el grupo de asociación de EAFRm a ácido tánico al 5\% presentaba un grado de retracción y reeptelización con mayor potencial de curación en comparación con los otros grupos.El estudio mostró la importancia del rendimiento histomorfométrico en la correlación con los hallazgos encontrado 
Palabras Clave: Rizophora mangle, ácido tánico, poder curativo, análisis morfométrico, análisis histomorfométrico

\begin{abstract}
Mangroves are economically important resource-rich areas exploited by the coastal human population. Rizophora mangle (Rhizophoraceae) is one of the species found in mangroves and is used in folk medicine to treat diarrhea, scarring, anti-inflammatory. Tannic acid which is also a component found in nature is popularly used as Antioxidant, astringent, bactericidal, This study aimed to investigate the antibacterial activity of the association of R.mangle aqueous leaf extract (EAFRm) associated with 5\% tannic acid. This is a study that induces the first intention wound to evaluate the healing potential when treated with some drugs, such as NACL, 4\% lannete cream, 5\% dexpanthenol and the combination cream described above (EAFRm). The botanical material was collected at the Mangrove of Itamaracá city, Vila Velha district in Pernambuco state - Brazil authorized by the Environmental Pollution Control and Water Resources Management Company (CA DFRB N. $120 / 2014^{\circ}$ ). The extract was prepared by shredding fresh leaves. The infusion was prepared with distilled water $\left(40^{\circ} \mathrm{C}\right.$ for 10 minutes) and filtered. It was then removed to L101 of the Liobras brand. After this procedure, the dried extract residue was stored at $5^{\circ} \mathrm{C}$. The tannic acid $(250 \mathrm{~g})$ was obtained as a water soluble powder with gallic acid content (dry basis) Max. 3.0\% / Density $0.350 .45 \mathrm{~g}$ / $\mathrm{cm} 3 / \mathrm{pH}$ ( $1 \%$ in water) 3, 04.0 / Solubility (20\% in water). The cream was produced at 5\% incorporated to the extract of Rizophora mangle to tannic acid. Twenty 8-week-old Wistar rats (Rattus novergicus) were selected and divided into 5 distinct groups. The project was approved by the Ethics Committee under No. 23076 .027569. / 2017-91. Induction of skin wounds that were treated and observed through clinical examination, morphometric analysis and histomorphometric analysis. Skin wounds were induced and then treated with clinical evaluation. After the procedure, morphometric and histomorphometric analysis were performed. the groups and evaluated it was observed that the association group of EAFRm to $5 \%$ tannic acid presented degree of retraction and reeptelization with higher healing potential when compared to the other groups. The study showed the importance of histomorphometric performance in the correlation with the findings found
\end{abstract}

Keywords: Rizophora mangle, tannic acid, healing power, morphometric analysis, histomorphometric analysis.

\title{
Introdução
}

Nas costas equatoriais dominadas por maré,os manguezais são abundantes e apresentam grande importância ecológica e também econômica.

Os sedimentos,invertebrados bentônicos e vegetação estão intimamente relacionados no ambiente de mangue e interagem de forma integrada,sendo desta forma essencial que sua plantação seja estudada de forma a conhecer sua relação com os outros seres vivos que vivem neste ambiente e também sua importância para a comunidade que se utiliza dos recursos do manguezal seja de forma direta ou indireta.

(Abeysinghe, P.D., 2010). 
A indústria de fitoterápicos e plantas medicinais do Brasil tem sido um desafio a ser vencido,pois representa uma excelente alternativa para a área de saúde por tratar-se de matéria prima de baixo custo,recurso renovável ,acessibilidade para a população como um todo.Se faz necessário que haja cada vez mais estudos e pesquisas para que se conheçam os metabólitos secundários de plantas medicinais para que haja eficácia e segurança na sua aplicação como medicamento sem que coloque em risco a vida das pessoas que utilizam tais fitoterápicos (Bras-Filho,1994)

Os compostos secundários são usualmente classificados de acordo com a sua rota biossintética. As principais famílias de moléculas geralmente consideradas são: os compostos fenólicos, terpênicos, esteróides, e os alcalóides. (Harbone, 1999; Pereira; Cardoso, 2012).

A função dos compostos fenólicos está envolvida com a síntese das ligninas que são comuns a todas as plantas superiores, atrativos aos seres humanos devido ao odor, sabor e coloração agradáveis, mas também para outros animais, os quais são atraídos para polinização ou dispersão de sementes. Além disso, esse grupo de compostos é importante para proteger as plantas contra os raios ultravioleta, insetos, fungos, vírus e bactérias (Croteau et al., 2000).

Os flavonóides são substâncias fenólicas de baixo peso molecular e estão amplamente distribuídas no Reino Vegetal, com estruturas baseadas no esqueleto heterocíclico aromático, 2-fenilbenzopirona ou 3-fenilbenzopirona contendo 15 átomos de carbono no seu esqueleto básico. Possuem múltiplos efeitos biológicos, como atividade antioxidante, antiinflamatória e antitumoral, poder de redução da fragilidade e permeabilidade capilares; inibição da destruição do colágeno e da agregação plaquetária. Assim, a ingestão de flavonóides está associada à longevidade e à redução na incidência de doenças cardiovasculares (Araújo, 2008).

Os taninos são classificados em dois grupos: hidrolisáveis e condensados. Os dois principais hidrolisáveis são os galotaninos e os elagitaninos. Os condensados são conhecidos como protoantocianidinas. Algumas espécies de plantas podem conter até $50 \%$ de tanino em material jovem seco; e em geral a maior concentração ocorre nos caules. (Cannas, 2008).

Os taninos são conhecidos por suas atividades antimicrobianas, além de relatos de agirem sobre o metabolismo do ácido araquidônico em leucócitos com papéis importantes nas 
inflamações (Okuda, 2005) e são utilizados em tratamentos que promovem a cicatrização de feridas (Perera et al., 2001;Ofori-Kwakye et al.,2011).

Os terpenóides representam a segunda maior classe de metabólitos secundários com o maior número de constituintes ativos. São classificados a depender da sua fórmula molecular. Um dos terpenóides conhecidos são os triterpenos que são constituídos por 6 unidades de isoprenos. Apresentam diversas atividades biológicas, entre as quais destacam-se: cardioprotetora (Sudhahar, et al. 2007), gastroprotetora (Pertino, et al. 2007), antiinflamatória (Medeiros, et al. 2007), antitumoral (Braga, et al., 2007), anti-hiperglicêmica (Sato, et al. 2007). e leishmanicida (Delgado-Mendez, et al. 2008).

Os alcalóides podem ser definidos como compostos farmacologicamente ativos, contendo um nitrogênio e derivados de aminoácidos (Cordell, 1981). Entretanto os alcalóides não são distribuídos de maneira uniforme no reino vegetal e são mais específicos para alguns gêneros de plantas (Andrade et al., 2012).

Diante das atividades biológicas e farmacológicas supracitadas, o uso popular não é suficiente para validar eticamente as plantas medicinais como medicamentos eficazes e seguros. Faz-se necessário a realização de estudos toxicológicos para a avaliação de parâmetros de segurança, os quais não são observados apenas pela utilização popular dessas plantas. (Oliveira et al., 2013)

\section{Fundamentação Teórica}

Nesta parte do artigo, o autor deve fazer uma exposição e uma discussão das teorias que foram utilizadas para entender e esclarecer o problema, apresentando-as e relacionando-as com a dúvida investigada. A fundamentação apresentada servirá de base para as análises dos dados, no momento da apresentação e discussão dos resultados.

\section{Metodologia}

\section{Coleta do material vegetal}

As folhas da Rhizophora mangle foram coletadas no mangue do município de Itamaracá-PE. Uma exsicata foi identificada pela bióloga Marlene Barbosa e encontra-se no 
Herbário da UFPE sob número UFP. 69.655. A coleta foi autorizada pelo Companhia Pernambucana de Controle da Poluição Ambiental e de Administração de Recursos Hídricos sob número autorização CA DRFB No 120/2014

\section{Obtenção do ácido tânico sintético}

A obtenção do ácido tânico $(250 \mathrm{~g})$ foi realizada comercialmente em forma de pó hidrossolúvel com teor de ácido gálico (base seca) Max. 3,0\%/ Densidade 0,35 0,45g/cm3/ pH (1\% em água) 3,0 4,0/ Solubilidade (20\% em água) .

\section{Preparação do extrato aquoso}

O extrato aquoso de folhas de Rizophora mangle foi preparado por trituração de 1 quilo de folhas frescas e submetidas à infusão com água destilada $\left(40^{\circ} \mathrm{C}\right.$ por 10 minutos $)$, e filtrado.

\section{Obtenção do creme}

O creme foi produzido a $5 \%$ em uma associação de Rizophora mangle ao ácido tânico com a utilização de papel manteiga até atingir $3 \mathrm{~g}$ e vertido em gral de porcelana e solubilizado com água destilada e homogeneizado.

\section{Animais}

Foram utilizadas vinte ratas fêmeas da raça wistar (Rattus norvegicus) com idade de 8 a 12 semanas de vida,da mesma linha reprodutiva com peso de 250 e 300 gramas,divididas em 4 grupos de 5 animais cada, que foram marcadas, pesadas e divididas aleatoriamente em quatro grupos :Grupo G1-tratadas com NACL ;Grupo G2 - tratadas com creme lannete a 4\% ; Grupo G3 -tratadas com dexpantenol a 5\% ;Grupos G4 - tratadas com associação em creme de EAFRm ao ácido tânico a 5\%

\section{Aspectos Bioéticos}

Os métodos utilizados neste estudo, aprovados pela Comissão de Ética no uso de Animais (CEUA) da UFPE com processo de número:23076.027569/2017- 91 segue a Diretriz Brasileira para o Cuidado e a Utilização de Animais para fins Científicos e Didáticos - DBCA do Conselho Nacional de Controle de Experimentação Animal - CONCEA do Ministério da Ciência, Tecnologia e Inovação.

Os animais foram mantidos a $27 \pm 2{ }^{\circ} \mathrm{C}$, com umidade relativa 44 a $56 \%$ e ciclos de luz e escuro de 10 e $14 \mathrm{~h}$, respectivamente, durante 1 semana antes e durante os experimentos. Os animais receberam dieta padrão (Labina purina ${ }^{\circledR}$, Brasil) e água ad libitum .

\section{Avaliação do Potencial Cicatrizante}

Todos os grupos de animais citados acima foram submetidos à indução de lesão ,os quais foram previamente anestesiados com uma associação de ketamina/xilazina e tricotomizados na região dorsal em área de $4 \mathrm{~cm}^{2}$.A área para a indução da lesão foi 
demarcada e retirada com a utilização de um bisturi com lâmina estéril de $\mathrm{n}^{\circ} 15$ até a fáscia muscular dorsal. Os animais foram avaliados morfometricamente após o $5^{\circ}$ dia do procedimento e nos $10^{\circ}$ e $15^{\circ}$ dias, respectivamente foram induzidas novas lesões para análise morfo e histomorfométrica.

\section{Análise Morfométrica}

A atividade cicatrizante foi avaliada através da mensuração, por paquímetro universal da marca Digimess, dos tamanhos da ferida cirúrgica antes da utilização das substâncias valores iniciais de comprimento e largura; e a avaliação final da cicatriz no $5^{\circ}, 10^{\circ}$ e $15^{\circ}$ dia de pós-operatório.

\section{Remoção da Cicatriz e Análise Histomorfométrica}

Ao final de cada subgrupo no $10^{\circ}$ e $15^{\circ}$ dias, realizou-se nova intervenção cirúrgica com remoção da cicatriz com margem de $1 \mathrm{~cm}$ de pele em torno da lesão, com profundidade até a musculatura dorsal do animal, e colocadas em solução tamponada de formol a $10 \%$. Após fixação as amostras foram processadas em técnica histológica convencional.

\section{Análise Estatística}

Os dados foram analisados através das medidas de estatística descritiva: média, desvio padrão e mediana e inferencialmente através dos testes estatísticos: Sigma (versão: 2.23.03). Foram utilizados os testes de Wilcoxon e Mann-Witney na comparação entre grupos.

\section{Resultados e Discussão}

A inspeção das feridas operatórias revelou que o grupo I e II apresentaram crostas e tecido de granulação com processos infecciosos das feridas durante o período do estudo. Entretanto, o grupo III, apresentou crostas e cicatriz sem infecção de ferida cirúrgica. Estes resultados sugerem diferentes mecanismos de ação dos compostos secundários presentes na planta. O gênero Rhizophora possui determinadas substâncias presentes no extrato, como por exemplo, os taninos e polifenóis (Bandaranayake, 2002), que são capazes de interagir com estruturas peptídicas formando grandes aglomerados, o que mais uma vez explicaria a formação da película protetora (Fernandez et al., 2002; Perera et al., 2010).

Chen et al. (1994) utilizaram preparação a base de taninos em feridas cutâneas. Esta película deve estar relacionada ao complexo formado por taninos não hidrolisáveis com proteínas, o qual pode exercer uma ação protetora isolando a ferida do ambiente. Resultados semelhantes foram encontrados Fernandez et al. (2002) que observaram uma película 
vermelha escura cobrindo as feridas de cisto pilonidal nos pacientes tratados com o extrato de caule de $R$. mangle $L$. Não houve infecções secundárias no local, as feridas estavam secas durante todo o processo de avaliação clínica. Outra hipótese é que ação antibacteriana dos taninos diminuam o risco de infecção de ferida, evitando o retardo da cicatrização. Melchor et al. (2001) estudaram o extrato aquoso do caule da R. mangle L. demonstrando propriedades antibacterianas atribuindo a ação aos constituintes polifenólicos presentes no extrato.

Estudos fitoquímicos de extratos do caule da $R$. mangle L. evidenciaram a presença de taninos. (Melchor et al., 2001; Bandaranayake, 2002; Marrero et al., 2006; Berenguer et al., 2006; De- Faria et al., 2012). Bueno et al (2014) reforçou que os taninos influenciam na fisiologia das células da pele através das suas propriedades farmacológicas, aumentando a proliferação celular.

Os resultados da avaliação das áreas das feridas cirúrgicas no $10^{\circ}$ dia de pósoperatório mostraram uma redução superior dos grupos II e III com significativo nível de retração da ferida,quando comparados ao grupo I. Foi no grupo IV que houve maior grau de contração em relação ao quinto dia entre os animais do mesmo grupo e de outros grupos. No décimo dia o grau de retração da ferida operatória alcançou 68,27\% em relação ao primeiro dia de indução da ferida, enquanto que nos grupos I, II e III foram $26,75 \%, 20,0 \%$ e 52,82\%, respectivamente, em relação ao primeiro dia de indução da ferida. No $15^{\circ}$ dia, houve um grau satisfatório de contração em todos os grupos estudados. A granulação foi positiva, mas em relação ao percentual de contração das feridas cutâneas, houve maior retração no grupo IV, tanto em relação aos demais grupos quanto em dias anteriores. A retração das feridas do grupo IV do décimo quinto dia alcançou 99\%. No exame clínico das feridas cirúrgicas, evidenciaram-se diferentes características entre os 4 grupos. No subgrupo I, houve secreções purulentas em dois animais com resolução espontânea durante o processo cicatricial. No subgrupo, ocorreu a formação de tecido de granulação e crosta em todos os animais. No final do $15^{\circ}$ dia, a pequena crosta estava presente na maioria dos ratos.

As feridas dos grupos mostraram crostas e tecido de granulação nos animais. O grupo III revelou uma uniformidade de aspecto da ferida, sem secreções purulentas nas feridas operatórias, e regularmente, apresentaram uma boa cicatriz macroscópica. Neste estudo, a análise morfométrica de feridas cirúrgicas através de áreas da $5^{\mathrm{a}}, 10^{\mathrm{a}}$ e $15^{\mathrm{a}}$ lesões pósoperatórias demonstrado na Tabela .No $5^{\circ}$ dia, os três grupos tiveram uma redução da área da ferida, mas sem diferença estatística significante. No décimo dia de pós-operatório, os grupos 
II e III foram semelhantes quando comparados ao grupo I. Enquanto que no $15^{\circ}$ dia próspero, a medida da área final no grupo II foi maior que nos demais grupos.O grupo IV mostrou-se muito mais eficaz em sua cicatrização em todos os dias de avaliação com relação aos demais grupos.

Estes resultados corroboram com os estudos pré-clínicos de Sánchez et al (2009), que estudaram a ação cicatricial de extratos de Rizophora mangle em feridas cutâneas abertas de ratos com redução das áreas no $5^{\circ}$ dia de pós-operatório.

Em todos os grupos no $15^{\circ}$ dia de pós-operatório, houve redução das áreas das feridas porém sem diferença estatisticamente significante entre os grupos. Sabe-se que o processo cicatricial depende do tempo da injúria inicial, e que a terceira fase das etapas de cicatrização inclui o remodelamento da cicatriz com contração das feridas ou até mesmo a sua hipertrofia. (Kirsner at., 2008) .

Contudo, as feridas abertas apresentam padrões clínicos diferentes das feridas incisas e tratadas. Embora os processos morfológicos e químicos básicos, que atuam na ferida fechada, sejam os mesmos nas feridas abertas em cicatrização, a contração torna-se um aspecto importante nas feridas abertas, e a epitelização assume um papel proeminente (Coelho et al, 1999). Os dois processos parecem ser independentes (Madden \& Arem, 1991). A contração da ferida é favorecida nos locais onde a pele é mais frouxa e móvel, como a pele do tronco (Ramsey et al., 1995). A mobilidade cutânea depende da direção das "linhas de Langer", que é determinada pela disposição do sistema fibrilar da pele, sobretudo das fibras elásticas. A distensão máxima acontece em direção transversal às linhas de Langer, motivo pelo qual a contração da ferida ocorre nesta direção (Algower, 1977). Portanto, sugerimos que o resultado das áreas finais ocorreram pelo formato da ferida cirúrgica com aumento da força de tensão na terceira fase da cicatrização. Para a produção das feridas de forma quadrada ou retangular, a pele foi incidida no sentido longitudinal e transversal, determinando aumento da área, devido à distensão provocada pela incisão transversal às linhas de Langer, conforme ressaltou Algower (1977).

Apesar do vasto uso popular da R. mangle L., os estudos correlacionando com poder cicatrizante sempre utilizaram os extratos provenientes do caule, porém a população geral usa infusões das folhas pela facilidade de coleta. (Medeiros et al, 2004; Pinto et al., 2006; Giraldi e Hanazaki, 2010). Nosso estudo, utilizou o extrato da folha com veículo creme a fim de avaliar seu potencial e corroborar com uso popular. 
Este estudo, ao mensurar a distância entre os epitélios, demonstrou que no $10^{\circ}$ dia de pós-operatório o EAF R.mangle associado ao ácido tânico a 5\% em creme foi semelhante ao dexpantenol a $5 \%$ em creme, e ambos diferentes do grupo em que foi usado o soro fisiológico a $0,9 \%$. Este dado sugere que o EAF R.mangle a $5 \%$ em creme contribui para acelerar a reepitelização. O dexpantenol a $5 \%$ já é comercializado e tem um amplo uso na medicina convencional com bons benefícios: cicatrizante, hidratante e mantenedor do trofismo mucocutâneo (Stozkowska e Piekos, 2004; Heise et al, 2012 e Biro et al, 2003).

No $15^{\circ}$ dia de pós-operatório, todos os animais tratados com EAF R.mangle associado ao ácido tânico a 5\% em creme apresentaram reepitelização completa, com significância estatística quando comparado aos grupos I e II, corroborando com os estudos científicos que sugerem que o extrato desta planta possui efeitos cicatrizantes. (Perera et al., 2001 e Fernandez et al, 2002).

A cicatrização de feridas é um processo dinâmico, interativo e iniciado em resposta a uma injúria (Guo e Dipietro, 2010), cujo objetivo é restaurar a continuidade anatômica efuncional do tecido, sendo essencial para a manutenção da integridade do organismo (Barbul,1990; Broughton et al., 2006; Thornton et al., 1997). Dessa forma, um grande número de investigações e estudos clínicos têm sido realizado com o intuito de melhorar o processo cicatricial das feridas (Gál et al., 2009) e consequentemente a qualidade de vida das pessoas.Este é o primeiro estudo que aborda o potencial terapêutico em relação à cicatrização da associação de Rizophora mangle ao ácido tânico em base creme a 5\%. É importante salientar que o gênero Rizophora possui constituintes químicos que podem apresentar diversas propriedades farmacológicas, como os alcaloides, taninos, flavonóides, saponinas e triterpenos (Abeysinghe, 2010; Ghani, 1998;Vadlapudi, 2012), que contribuem para a ação medicamentosa desta planta.

$\mathrm{Na}$ avaliação das feridas cirúrgicas, o grupo I apresentou secreções purulentas durante os primeiros três dias de tratamento. No grupo IV, a formação de tecido de granulação e crosta ocorreu em todos os animais em um período de 2-3 dias.Araújo (2015) estudando feridas cirúrgicas em camundongos tratados com R.mangle em creme revelou que o grupo tratado com R. Mangle apresentou feridas uniformes e não infectadas quando comparado aos grupos tratados com solução de $\mathrm{NaCl}$ e dexpantenol que apresentaram tecido de granulação com ferida infecciosa. 
O gênero Rhizophora possui certas substâncias presentes no extrato, como taninos e polifenóis (Bandaranayake, 2002), que são capazes de interagir com estruturas peptídicas formando grandes aglomerados, o que explicaria a formação do filme protetor. Este filme deve estar relacionado ao complexo formado por taninos não hidrolizáveis com proteínas, que podem exercer uma ação protetora ao isolar a ferida do meio ambiente (Fernandez et al. 2002, Perera et al. 2010). Fernandez et al. (2002) mostraram resultados semelhantes e observaram um filme vermelho escuro cobrindo as feridas do cisto pilonidal nos pacientes tratados com o extrato do caule de $R$. mangle L. Não houve infecções secundárias no local; as feridas estavam secas durante todo o processo de avaliação clínicaPerera et al. A avaliação da atividade anti-ulcerogênica do extrato de Rizhophora mangle L. mostrou a presença de uma camada espessa aderente à mucosa gástrica, sugerindo uma barreira física com propriedades gastroprotetoras semelhantes às observadas em feridas cutâneas.

Outra hipótese é que a ação antibacteriana dos taninos reduz o risco de infecção da ferida, evitando o retardo da cicatrização. Melchor et al. estudou o extrato aquoso do caule de Rhizophora mangle L. demonstrando propriedades antibacterianas atribuindo a ação aos constituintes polifenólicos presentes no extrato. Estudos fitoquímicos de extratos de caule de R.mangle L. mostraram a presença de taninos. Bueno et al reforçaram que os taninos influenciam a fisiologia das células da pele através de suas propriedades farmacológicas, aumentando a proliferação celular.

Os resultados da avaliação das áreas das feridas cirúrgicas no $10^{\circ}$ dia de pós-operatório mostraram uma redução superior nos grupos III e IV quando comparados aos grupos I e II. Em relação à inspeção das feridas operatórias este período, foi observado que o grupo do soro fisiológico e do creme lannete apresentaram crostas e tecido de granulação com processos infecciosos das feridas durante os primeiros dias do período do estudo. O grupo III ,tratado com dexpanntenol demonstrou uma bom processo de cicatrização e processo de contração satisfatório.Entretanto, o grupo IV de associação da Rizophora mangle ao ácido tânico em creme a 5\% apresentou crostas e cicatriz sem infecção da ferida cirúrgica. Estes resultados podem ser explicados por diferentes mecanismos de ação dos compostos secundários presentes na planta,como flavonoides e taninos, que são conhecidos por possuírem propriedades antimicrobianas e antioxidantes (Ofori-Kwakye et al., 2011). Nesse sentido, Santos et.al (2010) mostraram que o extrato aquoso da folha apresentou atividade antibacteriana in vivo, a qual pode contribuir para a ação cicatrizante desta associação , 
diminuindo o risco de infeção da lesão, que é a causa mais provável de retardo na cicatrização de feridas (Leaper, et al., 2015).A análise morfométrica revelou que a média das áreas da ferida diminuiu com a

progressão do tempo de avaliação em todos os grupos estudados.

Esses resultados corroboram com os estudos pré-clínicos de Sánchez et al. (2009), que estudaram a ação cicatricial de extratos de Rhizophora mangle L. em feridas cutâneas abertas de ratos com redução das áreas no $5^{\circ}$ dia de pós-operatório. Em todos os grupos, no $15^{\circ}$ dia de pós-operatório, houve redução das áreas da ferida. No entanto, feridas abertas apresentaram aspectos clínicos diferentes de feridas incisadas e suturadas. Embora os processos básicos morfológicos e químicos que atuam na ferida fechada sejam os mesmos na cicatrização de feridas abertas, a contração se torna um aspecto importante em feridas abertas, e a epitelização desempenha um papel proeminente (Coelho et al, 1999). Os dois processos parecem ser independentes (Madden \& Arem, 1991).

De acordo com Bueno et. al (2014), os taninos influenciam na fisiologia das células da pele através das suas propriedades farmacológicas, aumentando a proliferação celular. Sendo assim, o resultado do presente trabalho sugere uma ação mitogênica do extrato de EAF R.mangle por possuir este composto.

$\mathrm{Na}$ análise histomorfométrica demonstrou que a média da distância entre os epitélios da ferida cirúrgica foi mais elevada no grupo do soro fisiológico e no grupo do creme lannete após 10 dias, apresentando diferença estatística com os demais grupos; outra média que mostrou-se satisfatória foi o grupo tratado com dexpantenol a 5\% em creme ,porém ,a menor média foi observada no grupo que utilizou a associação da Rizophora mangle ao ácido tânico em creme a 5\% . O creme de dexpantenol é amplamente utilizado, pois indica melhorias na cicatrização de feridas (Heise et al., 2012; Oguz et al., 2015; Ulger et al., 2014), visto que penetra facilmente na pele em concentrações locais elevadas. Os efeitosmais significativos de formulações contendo dexpantenol incluem a estimulação da epitelização, granulação e o alívio de prurido (Ebner et al., 2002). Todavia, na avaliação após 15 dias de tratamento, todos os 5 animais medicados com a associação da Rizophora mangle ao ácido tânico em creme a $5 \%$ indicaram reepitelização completa das feridas. Isso pode ser atribuído à presença dos taninos nesta planta, pois eles contribuem para formação de uma camada protetora sobre a pele e as mucosas, atuando em processos inflamatórios, causando uma reestruturação do epitélio e a neovascularização (Simões et al., 2010). Esta película pode exercer uma ação 
protetora,isolando a ferida do ambiente, acelerando significativamente a reparação tecidual no grupo tratado com o creme de EAF R.m.Observou-se também, no presente estudo, que houve um aumento na quantidade de fibroblastos no grupo de EAF R.m associado ao ácido tânico a 5\% em creme, com diferença estatística, em comparação aos demais grupos estudadados e avaliados no intervalo de 15 dias. Ulger et al. (2014) acreditam que a melhora na taxa de cicatrização de feridas é devido ao aumento da proliferação de fibroblastos, bem como de uma epitelização acelerada. Além disso, vários outros estudos mostram a importância dos fibroblastos no processo cicatricial (Das, 2013; Diegelmann e Evans, 2004; Ebner et al., 2002; Khoshneviszadeh et al, 2014; Sonmez et al, 2015). Sugere-se que esta atividade estimuladora de fibroblastos da derme no grupo da planta estudada é devido à presença de taninos hidrolisáveis (Bueno et al., 2014).

$\mathrm{Na}$ análise histomorfométrica ficou demonstrado a nossa pesquisa que a média da distância entre os epitélios da ferida cirúrgica foi mais elevada no grupo do soro fisiológico após 10 dias, com diferença estatística aos demais grupos.A maior média observada no grupo IV, estatisticamente significativa foi o do dexpantenol a 5\% e com a Associação de EAF R.mangle ao ácido tânico. O creme de dexpantenol a 5\% é amplamente utilizado, pois indica melhorias na cicatrização de feridas (Heise et al., 2012; Oguz et al., 2015; Ulger et al., 2014), visto que penetra facilmente na pele em concentrações locais elevadas. Os efeitos mais significativos de formulações com dexpantenol a 5\% incluem a estimulação da epitelização, granulação e o alívio de prurido (Ebner et al., 2002). Todavia, na avaliação após 15 dias de tratamento, todos os 5 animais tratados com o creme a 5\% associado EAF R.mangle e ácido tânico indicaram reepitelização completa das feridas. Isso pode ser atribuído à presença dos taninos nesta planta, pois eles contribuem para formação de uma camada protetora sobre a pele e as mucosas, que atua em processos inflamatórios, causa uma reestruturação do epitélio e a neovascularização (Simões et al., 2010). Esta película pode exercer uma ação protetora que isola a ferida do ambiente e acelera significativamente a reparação tecidual no grupo tratado com o creme a 5\% de Associação de EAF R.mangle .

Observou-se também, no presente estudo, que houve um aumento na quantidade de fibroblastos no grupo de Associação de EAF R.mangle, com diferença estatística, em comparação aos demais no intervalo de 15 dias. Ulger et al. (2014) acreditam que a melhora na taxa de cicatrização de feridas é devido ao aumento da proliferação de fibroblastos, bem como de uma epitelização acelerada. Além disso, vários outros estudos mostraram a 
importância dos fibroblastos no processo cicatricial (Das, 2013; Diegelmann e Evans, 2004; Ebner et al., 2002; Khoshneviszadeh et al, 2014; Sonmez et al, 2015). Sugere-se que esta atividade estimuladora de fibroblastos da derme no grupo da planta estudada é devido à presença de taninos hidrolisáveis (Bueno et al., 2014).

Em nosso estudo, houve diferença estatística em relação à contração de feridas cirúrgicas no $15^{\circ}$ dia. A contração das feridas e a reepitelização foram eficazes em diversos processos de tratamento e cicatrização de feridas. Este estudo utilizou extrato aquoso de folhas de $R$. mangle associado ao ácido tânico em creme a 5\%,corroborando com os achados de eficácia no uso de hortaliças para a produção de fitoterápicos a partir da medicina popular.

Portanto, ressalta-se a importância da histomorfometria nos estudos, visto que somente a partir da análise microscópica foi possível avaliar o grau de reepitelização da ferida, demonstrado nos grupos que utilizaram creme de dexpantenol a 5\% e de Associação de EAF R.mangle ao ácido tânico foram bem superiores ao do soro fisiológico e ao creme lannete a $4 \%$, pois obtiveram um processo cicatricial mais rápido e eficiente. De todos os grupos analisados o que obteve os melhores resultados de cicatrização foi o de Associação de EAF R.mangle ao ácido tânico em creme a 5\%. Contudo, são necessários estudos mais aprofundados que comprovem o potencial cicatrizante desta planta, além de pesquisar outras atividades terapêuticas que esta espécie possa apresentar.

Os resultados do presente estudo mostraram que o uso tópico do EAF. $R$. mangle associado ao ácido tânico a 5\% em creme apresentam efeito significativo na reepitelização de feridas cirúrgicas em ratas. Partindo do princípio que a cicatrização é um processo dinâmico e multifatorial, este estudo evidenciou a importância da realização da histomorfometria na correlação com os achados morfométricos. Contudo, o isolamento de componente (s) da planta responsável(is) pela influência positiva no processo de reparação de tecidos deve ser realizado. A avaliação histomorfométrica do uso tópico do EAF. R. mangle associado ao ácido tânico a 5\% em creme apresentou efeito significativo na reepitelização de feridas cirúrgicas em ratas com fechamento completo entres os epitélios e ausência macroscópica de infecções. A análise morfométrica no $15^{\circ}$ dia do experimento não mostrou diferenças estatísticas entre a cicatriz dos animais tratados com creme lannete a $4 \%$ e soro fisiológico . Já a avaliação morfométrica no $15^{\circ}$ dia do experimento nos grupos tratados com dexpantenol a 5\% e no EAF R.mangle. associado ao ácido tânico a 5\% em creme mostrou diferenças 
estatísticas significativas quando comparadas aos animais tratados com soro fisiológico e creme lannete a $4 \%$.

Diante da certeza que a cicatrização é um processo dinâmico, multifatorial e histológico, este estudo reforça a importância da realização da histomorfometria na correlação com os achados morfométricos.

A associação entre o ácido tânico e a Rhizophora mangle demonstrou que as duas substâncias se potencializam reciprocamente por se tratarem de fármacos que apresentam taninos,substância essencial para a cicatrização de feridas.

A aplicação tópica do creme de folhas de Rhizophora mangle associadas com ácido tânico em creme a 5\% diminuiu a área da ferida, estimulou a reepitelização e aumentou o número de fibroblastos, exibindo uma ação cicatrizante nas lesões cutâneas em ratas mais eficiente do que o creme de dexpantenol a $5 \%$. Portanto, com a realização de novas pesquisas, este vegetal pode ser uma opção terapêutica alternativa no processo de reparação tecidual, trazendo vários benefícios à população.

A tabela abaixo mostra a média e o desvio padrão nos períodos de 5,10 e 15 dias,como também seu percentual de contração e seu valor de significância; cada período analisado e também seu valor de significância nestes mesmos períodos de análise.

\begin{tabular}{|c|c|c|c|c|}
\hline \multicolumn{5}{|l|}{ Período de Avaliação } \\
\hline \multirow{2}{*}{ Periodo de Avallaçao } & solução salina $\mathrm{NACL}$ ) & $\begin{array}{c}\text { Placebo Creme lannete a } \\
\qquad \% \text { ) }\end{array}$ & Dexpantenol a $5 \%$ & $\begin{array}{l}\text { Rhizophora manglet } \\
\text { Ácido tänico a } 5 \%\end{array}$ \\
\hline & $(n=5)$ & $(n=5)$ & $(n=5)$ & $(n=5)$ \\
\hline Após a cirurgia & Média + Desvio Padrão & Média + Desvio Padrão & Média + Desvio Padrāo & Média + Desvio Padrão \\
\hline Inicial & $4 \mathrm{~cm}^{2} \pm 0,00$ & $4 \mathrm{~cm}^{2} \pm 0,00$ & $4 \mathrm{~cm}^{2} \pm 0,00$ & $4 \mathrm{~cm}^{2} \pm 0,00$ \\
\hline 5 dias & $3,624 \mathrm{~cm}^{2} \pm 3,570 \mathrm{~cm}^{2}$ & $3,43 \mathrm{~cm}^{2} \pm 3,45 \mathrm{~cm}^{2}$ & $2,669 \mathrm{~cm}^{2} \pm 2,673 \mathrm{~cm}^{2}$ & $2,203 \mathrm{~cm}^{2} \pm 2,160 \mathrm{~cm}^{2}$ \\
\hline $\begin{array}{c}\text { \% contração com } 5 \\
\text { dias }\end{array}$ & $9.40 \%$ & $14.25 \%$ & $33.27 \%$ & $44.92 \%$ \\
\hline p & $p<0,03$ & $p<0,03$ & $p<0,03$ & $p<0,03$ \\
\hline 10 dias & $1,070 \mathrm{~cm}^{2} \pm 0,921 \mathrm{~cm}^{2}$ & $3,188 \mathrm{~cm}^{2} \pm 3,115 \mathrm{~cm}^{2}$ & $1,887 \mathrm{~cm}^{2} \pm 1,741 \mathrm{~cm}^{2}$ & $1,269 \mathrm{~cm}^{2} \pm 1,288 \mathrm{~cm}^{2}$ \\
\hline $\begin{array}{c}\text { \% contração com } 10 \\
\text { dias }\end{array}$ & $26.75 \%$ & $20.30 \%$ & $52.82 \%$ & $68.27 \%$ \\
\hline p & $p<0,05$ & $p<0,02$ & $p<0,02$ & $p<0,02$ \\
\hline 15 dias & $0,418 \mathrm{~cm}^{2} \pm 0,381 \mathrm{~cm}^{2}$ & $1,040 \mathrm{~cm}^{2} \pm 0,912 \mathrm{~cm}^{2}$ & $0,15 \mathrm{~cm}^{2} \pm 0,16 \mathrm{~cm}^{2}$ & $0,020 \mathrm{~cm}^{2} \pm 0,018 \mathrm{~cm}^{2}$ \\
\hline $\begin{array}{c}\% \text { contração com } 15 \\
\text { dias }\end{array}$ & $89.55 \%$ & $74 \%$ & $96.25 \%$ & $99.50 \%$ \\
\hline $\mathbf{p}$ & $p<0,05$ & $p<0,08$ & $p<0,05$ & $p<0,05$ \\
\hline
\end{tabular}

Fonte: Própria (2018) 


\section{ANÁLISE HISTOMORFOMÉTRICA COM 10 DIAS}

Figura 1.Secções histológicas de pele dorsal de ratos mostrando grupo controle negativo com NACL (a),grupo tratado com placebo -creme lannete a 4\% (b), tratado com dexpantenol a 5\% (c) e medicado com Associação de

EAF R.magle ao ácido tânico a 5\% (d). Todas as imagens mostram o grau de reepitelização após 10 dias de tratamento: Distância entre os epitélios( a e b) e reepitelização satisfatória(c e d). Coloração HE. Aumento 2x.

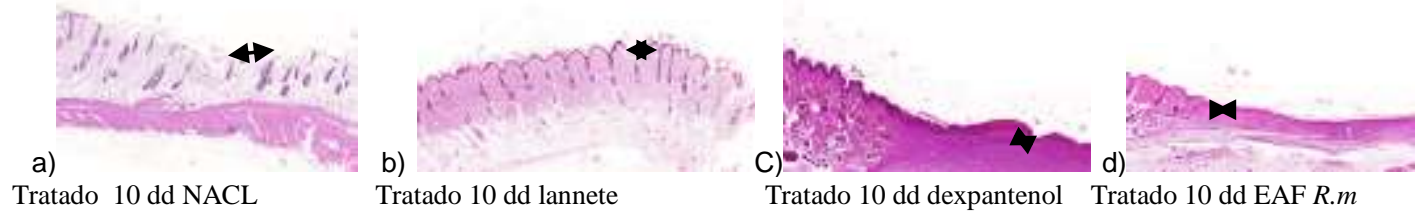

Fonte: Própria (2018)

\section{ANÁLISE HISTOMORFOMÉTRICA COM 15 DIAS:}

Figura 10: Secções histológicas de pele dorsal de ratos mostrando grupo controle negativo com NACL (a), tratado com Placebo-creme lannete a 4\% (b), grupo controle padrão com Dexpantenol a 5\% (c) e o grupo tratado com a Associação de EAF R.mangle ao ácido tânico a 5\% (d). Todas as imagens mostram o grau de reepitelização após 15 dias de tratamento: Distância entre os epitélios (a,b e c) e reepitelização total (d) Coloração HE. Aumento 2x.

a)

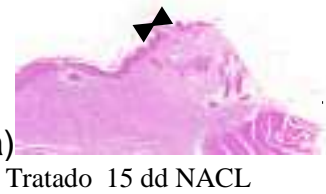

b)

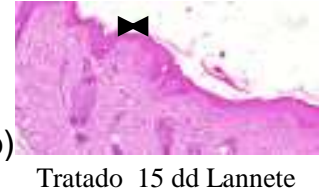

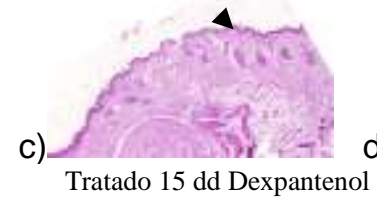

d)

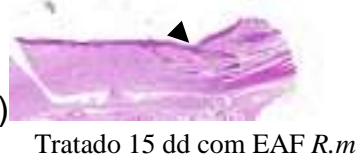

Fonte: Própria (2018)

\section{Conclusões}

A associação do extrato aquoso de folhas de Rizophora mangle e ácido tânico a 5\% mostra um potencial cicatrizante satisfatório no reparo tecidual de feridas cutâneas em ratas wistar.

De acordo com os aspectos macroscópicos das feridas cutâneas nos grupos de animais submetidos ao soro fisiológico,creme lannete a $4 \%$,dexpantenol a $5 \%$ em creme e a associação de extrato aquoso ao ácido tânico a $5 \%$,constatou-se que o grupo tratado mostrou que o creme de associação apresentou um maior índice de cicatrização em menor tempo em relação aos demais;

A análise morfométrica dos grupos tratados com seus fármacos distintos,demonstrou que área de cicatrização e o período de granulação das feridas são menores nos grupos tratados com dexpantenol a 5\% e o grupo tratado com a associação;

A análise histomorfométrica comprovaram que o grupo tratado com a associação apresentou um grau de reeptelização superior aos demais grupos tratados com outros fármacos. 
Este estudo mostrou que a espécie R.mangle associada ao ácido tânico em creme a $5 \%$ aplicado topicamente diminui a área da ferida de primeira intenção e estimula a reepitelização .Aumenta também o número de fibroblastos ,exibindo desta forma uma ação cicatrizante nas lesões cutâneas em ratas ,mostrando-se mais eficiente e eficaz do que o creme de dexpantenol a $5 \%$.

\section{Referências}

ABEYSINGHE, P.D. Antibacterial Activity of some Medicinal Mangroves against Antibiotic Resistant Pathogenic Bacteria. Indian J. Pharm. Sci. 72, 167-172. M. (1977) Manual de Cirurgia, Barcelona: Científicomédica, 3-14; 2010.

ARONS, J.A., WAINWRIGHT, D.J., JORDON, R.E. The surgical applications and aplications of cultured human epidermis: a comprehensive review. Surgery. 111(1),4-11; 1992.

Aspectos Nutricionais de Fitatos e Taninos, acesso em 05 de outubro de 2016;

BALSLEV, H. Juncaceae. Flora Neotropica Monograph 68:167pp. New York Botanical Garden, Nova York; 1996.

BALBINO, C.A., PEREIRA, L.M., CURI, R.Mecanismos envolvidos na cicatrização: uma revisão. Brazilian Journal of Pharmaceutical Sciences, vol 41, n. 1, jan./mar., 27-51. 2005.

BANDARANAYAKE, W.M. Bioactivities, bioactive compounds and chemical constituents of mangrove plants. Wetlands Ecology and Management, 10, 421-52; 2002.

BERENGUER, B.,et.al., Protective and antioxidant effects of Rhizophora mangle L. against NSAID-induced gastric ulcers. Journal of Ethnopharmacology. 103, 194-200; 2006.

BIRO, K., THACI, D., OCHSENDORF, F.R, KAUFMANN, R., BOEHCKE, W.H. Efficacy of dexpanthenol in skin protection against irritation: a double-blind, placebo-controlled study. Contact Dermatitis, 49, 80-84; 2003.

BUENO, F.G.,et.al.,. Hydrolyzable tannins from hydroalcoholic extract from Poincianella pluviosa stem bark and its wound-healing properties: Phytochemical investigations and influence on in vitro cell physiology of human keratinocytes and dermal fibroblasts. Fitoterapia 99, 252-260; 2014;

CURRIE, L.J., SHARPE, JR., MARTIN, R. The use of fibrin glue in skin grafts and tissueengineered skin replacements: a review. Plast Reconstr Surg. 108(6):1713-1726, 2001.

DAS, K. Wound healing potential of aqueous crude extract of Stevia rebaudiana in mice. Brazilian Journal of Pharmacognosy. 23, 351-357; 2013.

DE-FARIA, F. M.,et.al., Mechanisms of action underlying the gastric antiulcer activity of the Rhizophora mangle L. Journal of Ethnopharmacology. 139, 234- 243; 2012.

DE ARMAS,et.al., Efficacy of Rhizophora mangle aqueous bark extract (RMABE) in the treatment of aphthous ulcers: a pilot study. Current Medical Research and Opinion 21,17111715, 2005.

DE-FARIA,et.al.,(2009) Role of SOD in the protection of Rhizophora mangle on gastric injury induced by ethanol, ischaemia-reperfusion and acetic acid in rats. Planta Medica. 75, 1071, 2009.

DIEGELMANN, R.F., EVANS, M.C., Wound healing: an overview of acute, fibrotic and delayed healing. Front. Biosci. 9, 283-289, 2004. 
FERNANDEZ, O.,et.al.,(2002) Efficacy of Rhizophora mangle aqueous bark extract in the healing of open surgical wounds. Fitoterapia. 73, 564-568, 2002.

HEISE, R.,et.al., Dexpanthenol Modulates Gene Expression in Skin Wound Healing in vivo. Skin Pharmacol Physiol, 25, 241-248, 2012.

KHOSHNEVISZADEH,M.,et.al., Topical Simvastatin Enhances Tissue Regeneration in Fullthickness Skin wounds in rat models. Iran. J. Pharm. Res. 13,263-269, 2014.

KIRSNER, R.S.et.al., Cicatrização de feridas. In: Bolognia, Dermatologia. Rio de Janeiro:Ed. Elsevier., 141, 2147-2158, 2008.

LEITE, S.P., Indigofera Suffruticosa Mill: ensaio fitoquímico e ações biológicas biológicas. Universidade Federal da Paraíba, João Pessoa,2003.

MANDELBAUM,M.H.S., DI SANTIS, E.P. Cicatrização: conceitos atuais e recursos auxiliares: parte I. Anais Brasileiro de Dermatologia. 78 (5), 525-542, 2003.

SIMÕES,C.M.O. et.al., Farmacognosia: da Planta ao Medicamento, sexta ed. Porto Alegre/Florianópolis: Editora da Universidade UFRGS / Editora da UFSC, 2010.

SONMEZ, E.,et.al., The efficacy of absorbable polysaccharide haemostats in wound healing. Blood Coagul. Fibrinolysis. 26, 50-53, 2015.

ULGER,B.V.et.al., Comparing the effects of nebivolol and dexpanthenol on wound healing: anexperimental study. Int. Wound. J. 1-5. 2014. 